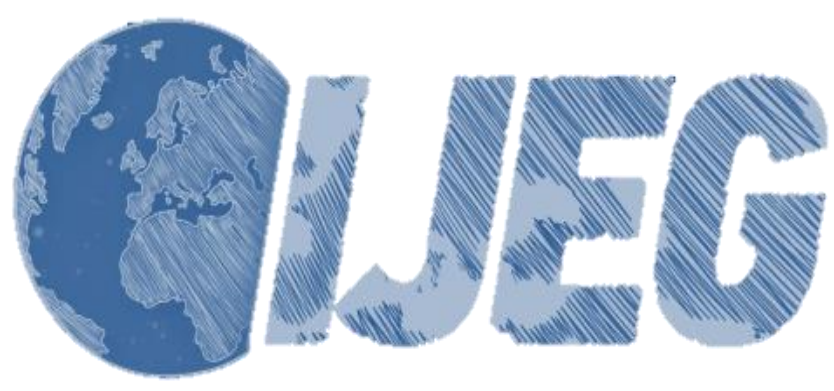

International Journal of Engineering and Geosciences (IJEG),

Vol; 5, Issue; 1, pp. 001-014, February, 2020, ISSN 2548-0960, Turkey, DOI:10.26833/ijeg.577385

\title{
PERFORMANCE ASSESSMENT OF IGS COMBINED/JPL INDIVIDUAL RAPID AND ULTRA-RAPID PRODUCTS: CONSIDERATION OF PRECISE POINT POSITIONING TECHNIQUE
}

\author{
Sermet Ogutcu* \\ Necmettin Erbakan University, Engineering Faculty, Department of Geomatic Engineering, Konya, Turkey \\ (sermetogutcu@konya.edu.tr); ORCID 0000-0002-2680-1856
}

*Corresponding Author, Received: 13/06/2019, Accepted: 25/07/2019

\begin{abstract}
Satellite orbit and clock products are the key elements for precise point positioning (PPP). Contrary to the relative technique, errors in satellite orbit and clock directly lump to the station coordinates for PPP technique. Currently final, rapid and ultra-rapid (observed-half and predicted-half) satellite products have been made freely available over the internet mainly for Global Positioning Service (GPS) satellites. Final and rapid products are used for post-processing applications. For real-time and near real-time applications, ultra-rapid products with predicted and observed parts can be used. There are several analysis centers that provide the satellite orbit and clock products. In this paper, accuracy and precision of GPS rapid and ultra-rapid satellite orbit and clock products from two services, International Global Navigation Satellite Service (IGS) and Jet Propulsion Laboratory (JPL), were investigated in the position domain of PPP technique while the final products of these services were taken as the true value. Ten IGS stations around the world were chosen for PPP processes. 24-12-8-4-2 hours of non-overlapping arc-lengths of GPS observations in 31 consecutive days (DOY 1-31 of 2018) were processed for each station. The results confirm that the shorter the arc-lengths, the larger the relative error of rapid and ultra-rapid products due to the similar Gaussian distribution pattern of the orbit errors with respect to the final products. In terms of consistency between the products, Root-Mean-Square-Errors (RMSE) of final-rapid differences of IGS and JPL are at the millimeter level. Millimeter level accuracy can be obtained using rapid and ultra-rapid products for JPL whereas only rapid products of IGS maintain millimeter accuracy with respect to the final products.
\end{abstract}

Keywords: Final orbits and clocks, GPS, IGS, JPL, Rapid and Ultra-Rapid products 


\section{INTRODUCTION}

With the developments of Global Positioning Service (GPS) satellite orbit and clock products, precise point positioning (PPP) could provide absolute positioning with millimetre (1-2 $\mathrm{mm}$ ) and sub-centimetre level (4-6 $\mathrm{mm}$ ) precision of daily solutions for horizontal and vertical components, respectively (Hayal and Sanli, 2016, Gao and Chen, 2004). PPP is gaining more popularity in the surveying community due to the simple and costeffective approach. GPS users can obtain a homogeneous positioning accuracy around the world through PPP using a single receiver without depending on any fiducial stations (Zumberge et al., 1997).

Since the release of International Global Navigation Satellite Service (IGS) (Dow et al., 2009), broadcast ephemeris (Montenbruck et al., 2015), final, rapid and ultra-rapid products (Springer and Hugentobler, 2001, http://www.igs.org/products) have undergone dramatic development. IGS analysis centers receive and process tracking data from GNSS networks then these solutions are merged to produce combined IGS orbit/clock products.

Currently five types of GPS satellite orbit and clock products are available. The broadcast ephemeris and the IGS ultra-rapid (predicted-half) products mainly aim for real-time applications, while the IGS rapid and final products aim for post-processing applications. According to IGS official website (http://www.igs.org/products), the nominal accuracies of broadcast orbits and clocks are reported as $\sim 1 \mathrm{~m}$ and $\sim 5 \mathrm{~ns}$, respectively (Tusat et al., 2018). Two types of ultra-rapid products are generated by IGS, one of which is observed-half with $3 \sim 9 \mathrm{~h}$ latency and the other is predicted-half without latency. The nominal accuracy of ultra-rapid observed-half and predicted-half orbits and clocks are reported as $3 \mathrm{~cm}$ and $\sim 150 \mathrm{ps}$ and $\sim 5$ $\mathrm{cm}$ and $\sim 3 \mathrm{~ns}$, respectively. The nominal accuracies of final and rapid orbits and clocks are reported as $\sim 2.5 \mathrm{~cm}$ and $\sim 75 \mathrm{ps}$, respectively.

The latency and accuracy differences between the products depend on the processing strategy and maximum used GNSS stations of the different Analyses Centers. The processing of final solutions includes minimal constraints to define the geodetic datum of the solutions. This means that only the sum of the rotations of a set of reference frame stations is constrained to be zero. For the rest, the reference frame of the solution is free in scale and origin. In the rapid and ultra-rapid solutions, the reference frame is determined by tightly constraining the $3 \mathrm{D}$ position of a set of selected reference GNSS stations. Due to the time constraints, rapid and ultra-rapid products typically use fewer stations compared to the final product.

The broadcast ephemeris and the IGS ultra-rapid (predicted-half) products are disseminating without latency. The latencies of IGS final, rapid and ultra-rapid (observed-half) products are 12-18 days, 17-41 hours and 3-9 hours, respectively. IGS ultra-rapid products update every six hours in order to decrease the divergence in orbit fitting throughout time. Each product is composed of $24 \mathrm{hr}$ of observed orbits and $24 \mathrm{hr}$ of predicted orbits.

The other commonly used GNSS service is the Jet Propulsion Laboratory (JPL) individual analysis centre. JPL has been providing GPS orbits and clocks since 1994 by processing data from the global network using GIPSY/OASIS scientific software (Bertiger et al., 2010).
According to the JPL official website (https://gipsyoasis.jpl.nasa.gov/index.php?page=data) threedimensional Root-Mean-Square-Errors (RMSE) of ultrarapid, rapid and final orbits and clocks are reported as 5, 3.5 and $2.5 \mathrm{~cm}$, respectively. All products are provided in formats native to GIPSY/OASIS. The latency of JPL final, rapid and ultra-rapid products are reported as < 14 days, Next-Day (16:00 UTC) and < 2 hours, respectively. JPL ultra-rapid product differs from IGS. JPL ultra-rapid product does not include predicted part, it includes only observed part. JPL does not participate nor contribute to the IGS ultra-rapid product.

IGS and JPL sample intervals of orbit and clock products are the same for final and rapid products (15 min for orbit and 5 min for clock). Since IGS does not produce monitor station clocks in the ultra-rapid products, the orbit and clock sampling intervals of IGS ultra-rapid products are the same and equals $15 \mathrm{~min}$. The orbit and clock sampling interval of JPL ultra-rapid product is 15 min and 5 min, respectively.

There is a significant delay between final and the other products and the trade-off between accuracy and time needed to be investigated properly. There are several studies that have been conducted in order to investigate the impact of using these products on the position domain.

Shi et al. (2017) investigated the impact of three types of real-time satellite products (broadcast, IGS ultra-rapid predicted-half and IGS-RTS CLK5 stream generated by CNES) on the position domain in relative technique while assuming the position from the final product is the true value. The results show that broadcast ephemeris provided $<2 \mathrm{~cm}$ relative positioning error for baselines no longer than $216 \mathrm{~km}$ while CNES product could result in $<5 \mathrm{~mm}$ relative positioning accuracy for baselines within $2982 \mathrm{~km}$, slightly better than the predicted ultra-rapid product. Lu and Li (2011) analyzed the impact of IGS broadcast, ultra-rapid and rapid products on PPP. The results show that broadcast ephemeris reaches sub-meter level accuracy while rapid and ultra-rapid reaches $\mathrm{cm}$ level accuracy. Park and Yung (2014) analyzed the impact of ultra-rapid (observed-half), rapid and final IGS products on PPP and relative technique. They found that the largest standard deviation of ultra-rapid is $3.9 \mathrm{~cm}$ for PPP while the standard deviation of rapid and precise ephemeris is less than $1 \mathrm{~cm}$. Yigit et al. (2017) assessed the PPP kinematic solutions based on both Natural Resources Canada (NrCAN) Ultra-Rapid products (commonly referred to as EMU) and IGS-Final products for detecting vertical dynamic oscillation. The results show that there is no significant difference between the IGS-Final and EMU-Ultra-Rapid products in terms of capturing dynamic oscillation. For relative positioning technique, the maximum standard deviation of ultra-rapid, rapid and final was reported as $1.4,1.5$ and $1.4 \mathrm{~cm}$, respectively. They did not report the baseline lengths for relative technique. Martin et al. (2011), computed the north, east and up differences between final-rapid and final-ultra rapid products for PPP positioning. The results show that rapid and ultra-rapid (observed-half) products are at $\mathrm{cm}$ level when compared with the solution obtained from final files. When ultra-rapid predicted-half products are used, the differences are slightly higher than the ultrarapid observed-half but still maintain $\mathrm{cm}$ level accuracy.

The above-mentioned studies only analyzed daily observations using IGS products which does not represent 
the real scenario most of the time and they did not consider different arc-lengths and other products from different analysis services. A comprehensive accuracy investigation of rapid and ultra-rapid products (observedhalf and predicted-half) for PPP position domain is virtually uncharted territory.

In this study, the accuracy of rapid and ultra-rapid products of IGS and JPL analysis centers was investigated for the position domain of PPP while their final products are taken as the true value.

\section{PPP OBSERVATION MODEL}

In general, ionosphere-free code and carrier phase observations are used for PPP in order to eliminate the first-order ionosphere effect. The equations can be written for phase and code observations as follows;

$P_{I F, r}^{S}=\rho+c *\left(d t_{r}-d t^{s}\right)+d_{\text {trop }}+H D_{P, r, I F}-$

$H D^{P, s, I F}+\epsilon_{P, I F}$

$\emptyset_{I F, r}^{S}=\rho+c *\left(d t_{r}-d t^{S}\right)+d_{\text {trop }}+\lambda_{I F} * N_{I F}^{S}+$

$H D_{\emptyset, r, I F}-H D^{\emptyset, s, I F}+\epsilon_{\emptyset, l f}$

where the superscript $s$ represents satellite, the subscript $r$ represents receiver, $P_{I F, r}^{S}$ and $\quad \emptyset_{I F, r}^{S}$ are the ionosphere-free combination of code and phase observations, $\rho$ is the geometric range in meters, $c$ is the speed of light in meters per second, $d t_{r}$ is the receiver clock offset in seconds, $d t^{s}$ is the satellite clock offset in seconds, $d_{\text {trop }}$ is the tropospheric delay in meters, $\lambda_{I F}$ is the ionosphere-free wavelength, $N_{I F}$ is the ionospherefree phase initial ambiguity, $H D_{P, r, I F}$ and $H D_{\emptyset, r, I F}$ are the ionosphere-free receiver hardware delay, $H D^{P, S, I F}$ and $H D^{\emptyset, S, I F}$ are the ionosphere-free satellite hardware delay and $\epsilon_{P, I F}$ and $\epsilon_{\emptyset, l f}$ are the ionosphere-free code and phase measurement noise.

The ionosphere-free code and carrier phase observables can be written as;

$P_{I F, r}^{S}=\left(f 1^{2} * P 1^{s}-f 2^{2} * P 2^{s}\right) /\left(f 1^{2}-f 2^{2}\right)$
$\emptyset_{I F, r}^{s}=\left(f 1^{2} * \emptyset 1^{s}-f 2^{2} * \emptyset 2^{s}\right) /\left(f 1^{2}-f 2^{2}\right)$

where $f 1$ and $f 2$ are two carrier-phase frequencies in Hertz and $P 1, P 2, \varnothing 1, \varnothing 1$ are the measured pseudorange and carrier phase in meters on two frequencies. Ionosphere-free wavelength and ionosphere-free ambiguity can be written as;

$\lambda_{I F}=\frac{f 1^{2}}{f 1^{2}-f 2^{2}} * \lambda_{1}-\frac{f 2^{2}}{f 1^{2}-f 2^{2}} * \lambda_{2}$

$N_{I F}=\frac{f 1^{2} * N_{1}}{f 1^{2}-f 2^{2}}-\frac{f 2^{2} * N_{2}}{f 1^{2}-f 2^{2}}$

where $N_{1}$ and $N_{2}$ are the phase initial integer ambiguities on two frequencies with respect to each observed satellite. As it is seen from Equation 6, ionosphere-free ambiguity can only be estimated as a float (real-value) unknown unless using bias information from the network. There are several sources of these biases for example, the noninteger uncalibrated hardware delays (UHD) originating in receivers and satellites (Geng et al., 2009) and widelane and dual-frequency phase bias information (Bertiger et al., 2010).

The estimated parameters include the threedimensional coordinates of the receiver, receiver clock offset, tropospheric zenith wet delay and ionosphere-free ambiguities.

\section{DATA PROCESSING}

10 IGS stations distributed around the world were chosen to perform PPP (Figure 1). When selecting the IGS stations, data availability and different satellite visibility of the stations were considered.

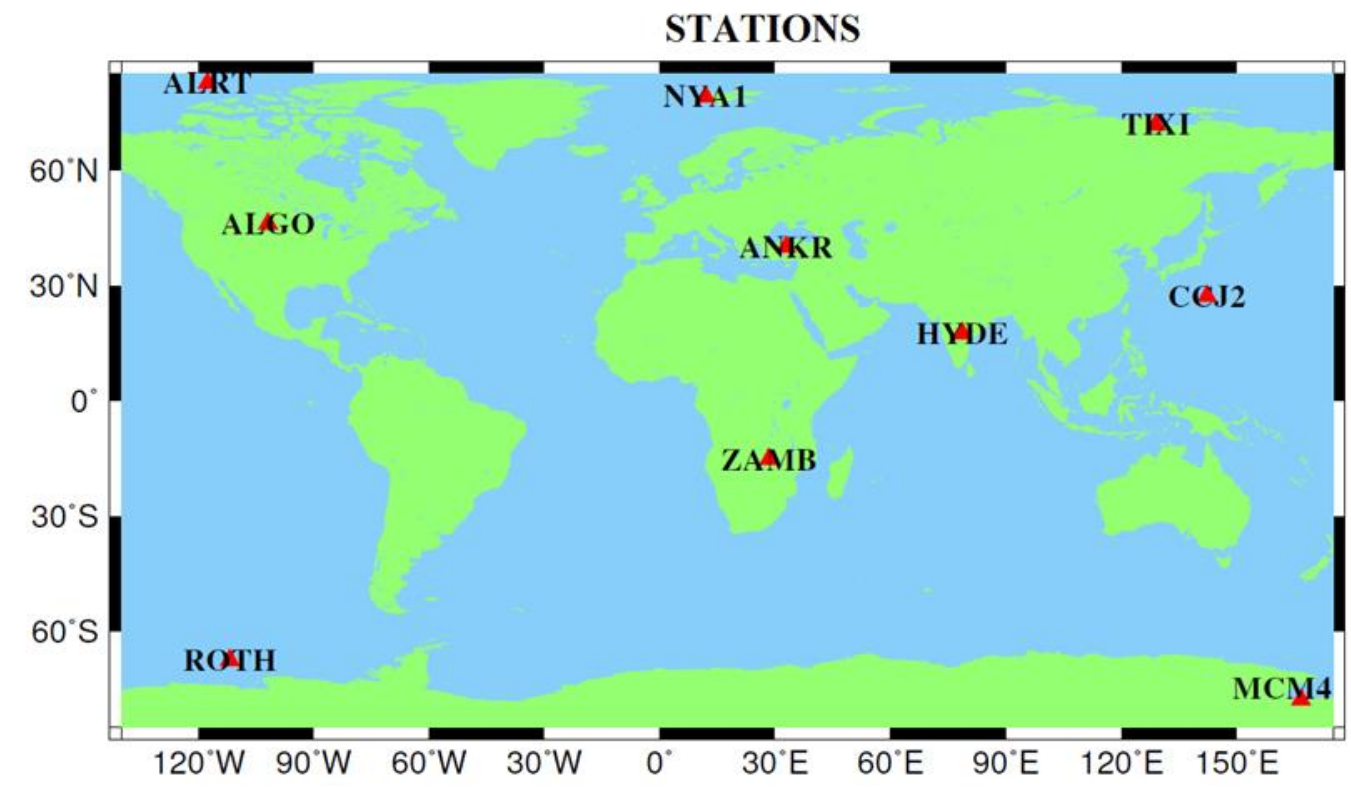


Figure 1. The distribution of the used IGS stations

31 consecutive days in the day of the year (DOY) 1 31 of 2018 were chosen to perform PPP. Each day's $24 \mathrm{~h}$ Receiver Independent Exchange (RINEX) data were mutually subdivided into 24-12-8-4-2 hours of nonoverlapping sessions for each station. Seven different IGS/JPL products namely, final, rapid, ultra-rapid observed-half and ultra-rapid predicted-half from IGS and final, rapid and ultra-rapid from JPL were processed for each station and each non-overlapping session. In order to represent the real scenario for near-real time PPP applications, most current available parts of IGS ultrarapid products with respect to the observation sessions were used in this study. For example, for $2 \mathrm{~h}$ nonoverlapping sessions include $00-04 \mathrm{~h}$ and $04-10 \mathrm{~h}$, iguxxxxx_06 (09 UTC) and iguxxxxx_12 (15 UTC) ultrarapid products were used. In this way, the jump in both the orbits and the clocks due to switching from one product to the next were avoided. Since JPL does not publicly provide the real-time products, JPL ultra-rapid product for real-time could not be processed in this study.

As a result, 150, 300, 450, 900 and 1800 PPP processing were conducted for 24-12-8-4-2 h subdivided RINEX data for each product, respectively. Epoch availability was checked for each daily RINEX file using in-house software. Threshold of epoch availability was set at $95 \%$ and the RINEX files below $95 \%$ availability were removed from the processing. In total, 6 daily RINEX files were not included for PPP.

GIPSY/OASIS 6.4 scientific software was used for PPP. GIPSY/OASIS is developed by NASA's Jet Propulsion Laboratory (JPL). Table 1 summarizes the processing parameters used in this study for PPP. The processing parameters were kept identical for each run except the used IGS/JPL products.

Table 1. Average DOP values of GNSS constellations

\begin{tabular}{|l|l|}
\hline Adjustment model & $\begin{array}{l}\text { Stochastic Kalman } \\
\text { filter/smoother } \\
\text { implemented as square } \\
\text { root information filter } \\
\text { with smoother }\end{array}$ \\
\hline Elevation cut-off angle & 7 degree \\
\hline $\begin{array}{l}\text { Weighting with } \\
\text { elevation }\end{array}$ & Applied \\
\hline Epoch interval & 300 seconds \\
\hline GNSS system & GPS \\
\hline Ionospheric effect & $\begin{array}{l}\text { Removed by L1, L2 } \\
\text { linear combination }\end{array}$ \\
\hline Phase initial ambiguity & $\begin{array}{l}\text { Estimated as real value } \\
\text { (float) }\end{array}$ \\
\hline $\begin{array}{l}\text { Data weight of linear } \\
\text { combination phase and } \\
\text { code }\end{array}$ & 1 cm / 1 m \\
\hline Antex file & $\begin{array}{l}\text { IGS14.atx (Rebischung } \\
\text { and Schmid, 2016) }\end{array}$ \\
\hline A priori troposphere & $\begin{array}{l}\text { GPT2 model (Lagler et } \\
\text { al., 2013) }\end{array}$ \\
\hline
\end{tabular}

\begin{tabular}{|l|l|}
\hline Zenith delay estimation & $\begin{array}{l}\text { random walk } 0.05 \mathrm{~mm} \\
\mathrm{~km} / \mathrm{sqrt}(\mathrm{sec})\end{array}$ \\
\hline $\begin{array}{l}\text { Horizontal delay } \\
\text { gradients estimation }\end{array}$ & $\begin{array}{l}\text { random walk 0.005 } \\
\mathrm{mm} / \mathrm{sqrt}(\mathrm{sec})\end{array}$ \\
\hline Troposphere gradients & Computed \\
\hline Code differential bias & Up to date DCB file \\
\hline Reference frame & ITRF14 \\
\hline Solid earth tide & IERS 2010 Conventions \\
\hline Pole tide & IERS 2010 Conventions \\
\hline $\begin{array}{l}\text { Earth Orientation } \\
\text { Parameter }\end{array}$ & IERS 2010 Conventions \\
\hline Ocean Tide Loading & IERS 2010 Conventions \\
\hline Eclipse strategy & $\begin{array}{l}\text { Eclipsing satellites were } \\
\text { not used until satellites } \\
\text { reach nominal attitude }\end{array}$ \\
\hline
\end{tabular}

IGS orbit and clock products were transformed to native GIPSY JPL products before processing. This transformation was performed using two scripts (igs2flinn.pl and sp3togoa.py) in GIPSY.

\section{RESULTS AND ANALYSIS}

RMSE of PPP processes using rapid and ultra-rapid products were computed while PPP results using IGS and JPL final products were taken as the true value with respect to each non-overlapping session. Estimated geocentric Earth Centered Earth Fixed (ECEF) coordinate differences were resolved to topocentric coordinates. Horizontal (2D) and vertical (Up) RMSE values of rapid and ultra-rapid products for the each session are shown in Figure 2-3. 


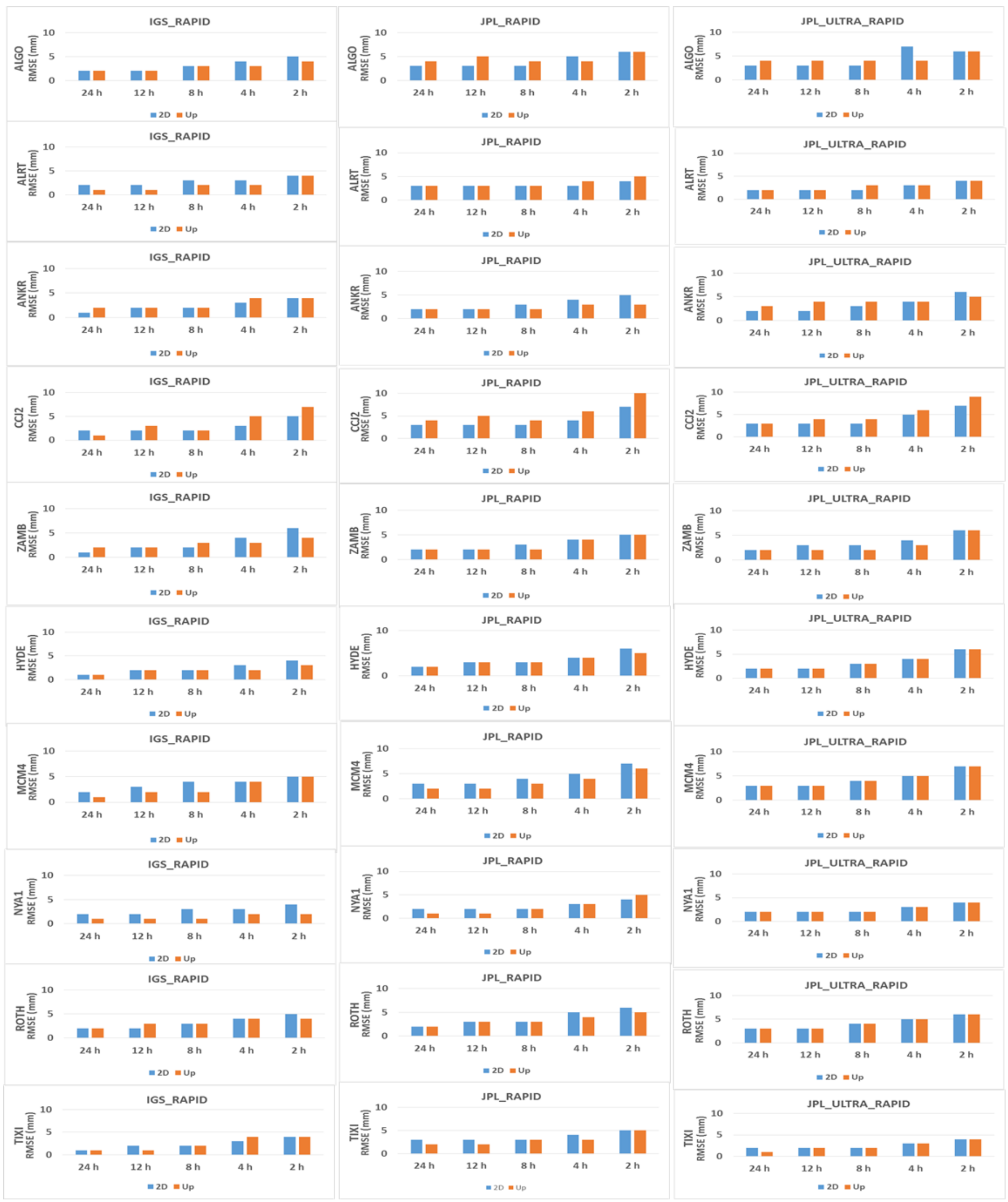

Figure 2. RMSE of PPP using JPL/IGS rapid and ultra-rapid products (Units: mm) 


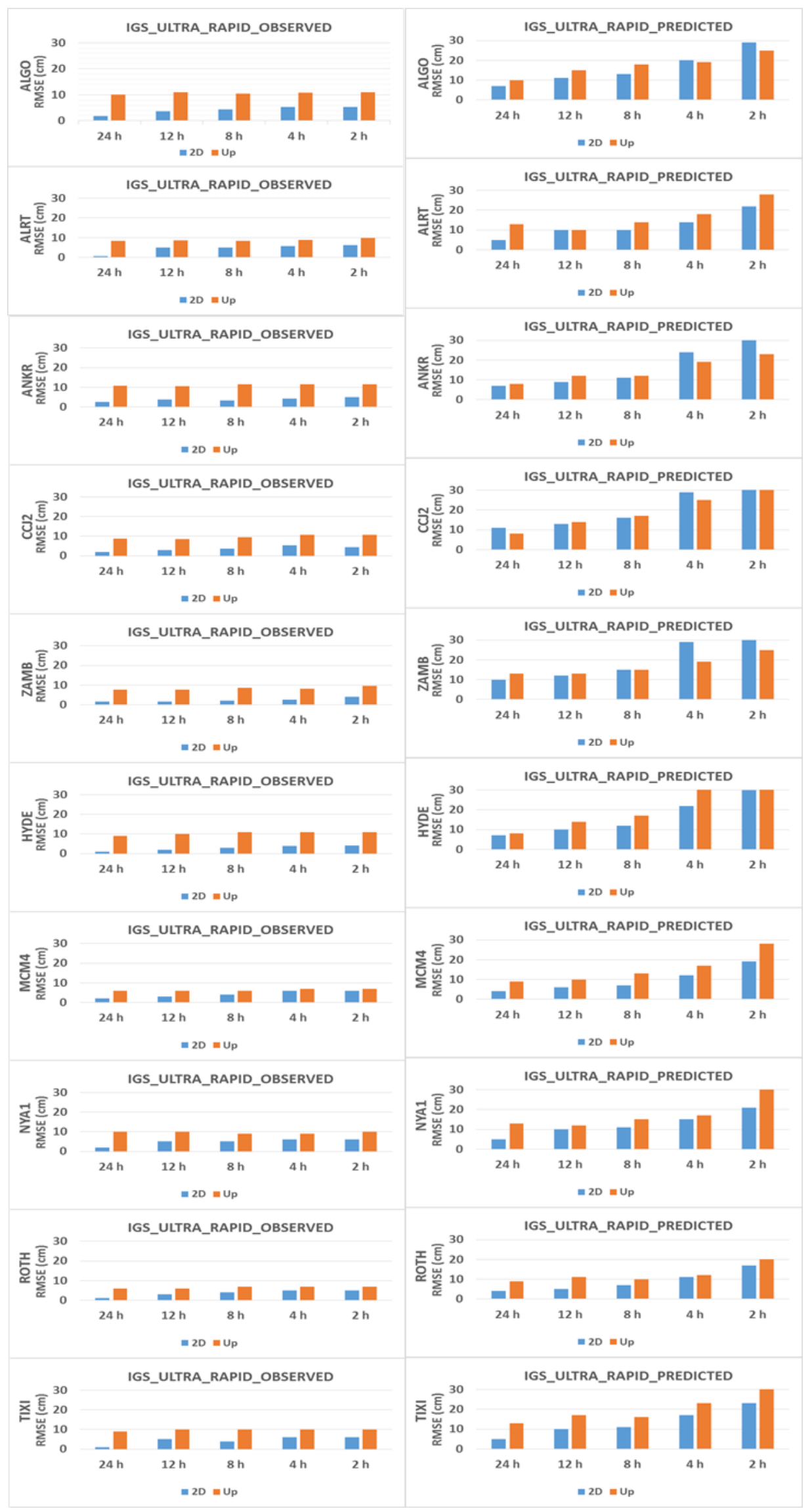

Figure 3. RMSE of PPP using IGS ultra-rapid product (Units: $\mathrm{cm}$ ) 
Table 2 shows the mean RMSE values of IGS stations for IGS rapid and JPL rapid/ultra-rapid products.

Table 2 Mean RMSE of PPP results using IGS rapid and JPL rapid/ultra-rapid products (Units: $\mathrm{mm}$ )

\begin{tabular}{|l|l|l|l|l|l|l|}
\hline & \multicolumn{2}{|l|}{ IGS Rapid } & \multicolumn{2}{c|}{ JPL Rapid } & \multicolumn{2}{l|}{$\begin{array}{l}\text { JPL Ultra- } \\
\text { Rapid }\end{array}$} \\
\hline Sessions & $2 \mathrm{D}$ & Up & $2 \mathrm{D}$ & Up & 2D & Up \\
\hline $\mathbf{2 4}$ & 2 & 1 & 2 & 2 & 2 & 2 \\
\hline $\mathbf{1 2}$ & 2 & 2 & 3 & 3 & 3 & 3 \\
\hline $\mathbf{8}$ & 3 & 2 & 3 & 3 & 3 & 3 \\
\hline $\mathbf{4}$ & 3 & 3 & 4 & 4 & 4 & 4 \\
\hline $\mathbf{2}$ & 5 & 4 & 5 & 5 & 6 & 6 \\
\hline
\end{tabular}

Table 3 shows the mean RMSE values of IGS stations for IGS ultra-rapid observed-half and predicted-half products.

Table 3 Mean RMSE of PPP results using IGS ultrarapid products (Units: $\mathrm{cm}$ )

\begin{tabular}{|c|c|c|c|c|}
\hline & \multicolumn{2}{|c|}{$\begin{array}{l}\text { IGS } \\
\text { Rapid Observed- } \\
\text { Half }\end{array}$} & \multicolumn{2}{c|}{$\begin{array}{c}\text { UGS } \\
\text { Rapid Predicted- } \\
\text { Half }\end{array}$} \\
\hline Sessions & 2D & Up & 2D & Up \\
\hline $\mathbf{2 4}$ & 2 & 9 & 6 & 10 \\
\hline $\mathbf{1 2}$ & 3 & 9 & 10 & 13 \\
\hline $\mathbf{8}$ & 4 & 9 & 11 & 15 \\
\hline $\mathbf{4}$ & 5 & 9 & 19 & 20 \\
\hline $\mathbf{2}$ & 5 & 10 & 26 & 28 \\
\hline
\end{tabular}

As it is seen from the RMSE values, PPP using IGS rapid, JPL rapid and JPL ultra-rapid products can maintain mm level of relative accuracy for horizontal and vertical components with respect to final product. JPL rapid and JPL ultra-rapid products produced nearly identical results. The JPL ultra-rapid product is much more useful for near real-time possible users (Senturk et al., 2017; Alcay et al., 2019) compared to the IGS ultrarapid observed-half product in terms of relative accuracy. The IGS ultra-rapid observed-half product maintains $\mathrm{cm}$ level relative accuracy whereas the IGS ultra-rapid predicted-half reaches $\mathrm{dm}$ level relative accuracy especially for short sessions.

The results indicate that when observing sessions shorter than $24 \mathrm{~h}$, the PPP differences between final and the other products are more prone to becoming high. It is believed that differences between orbit products follow the similar Gaussian distribution and this is mainly responsible for this phenomenon. Figure 4-5-6 show the distribution of ECEF differences within $24 \mathrm{~h}$ (DOY 001) between IGS final and rapid products for 01 (Block IIF), 05 (Block IIR-M) and 28 (Block IIR) PRN GPS satellites. A similar distribution has been observed for other GPS satellites and other products but are not given here due to limited space in this manuscript. 
International Journal of Engineering and Geosciences (IJEG), Vol; 5, Issue; 1, pp. 001-014, February, 2020,
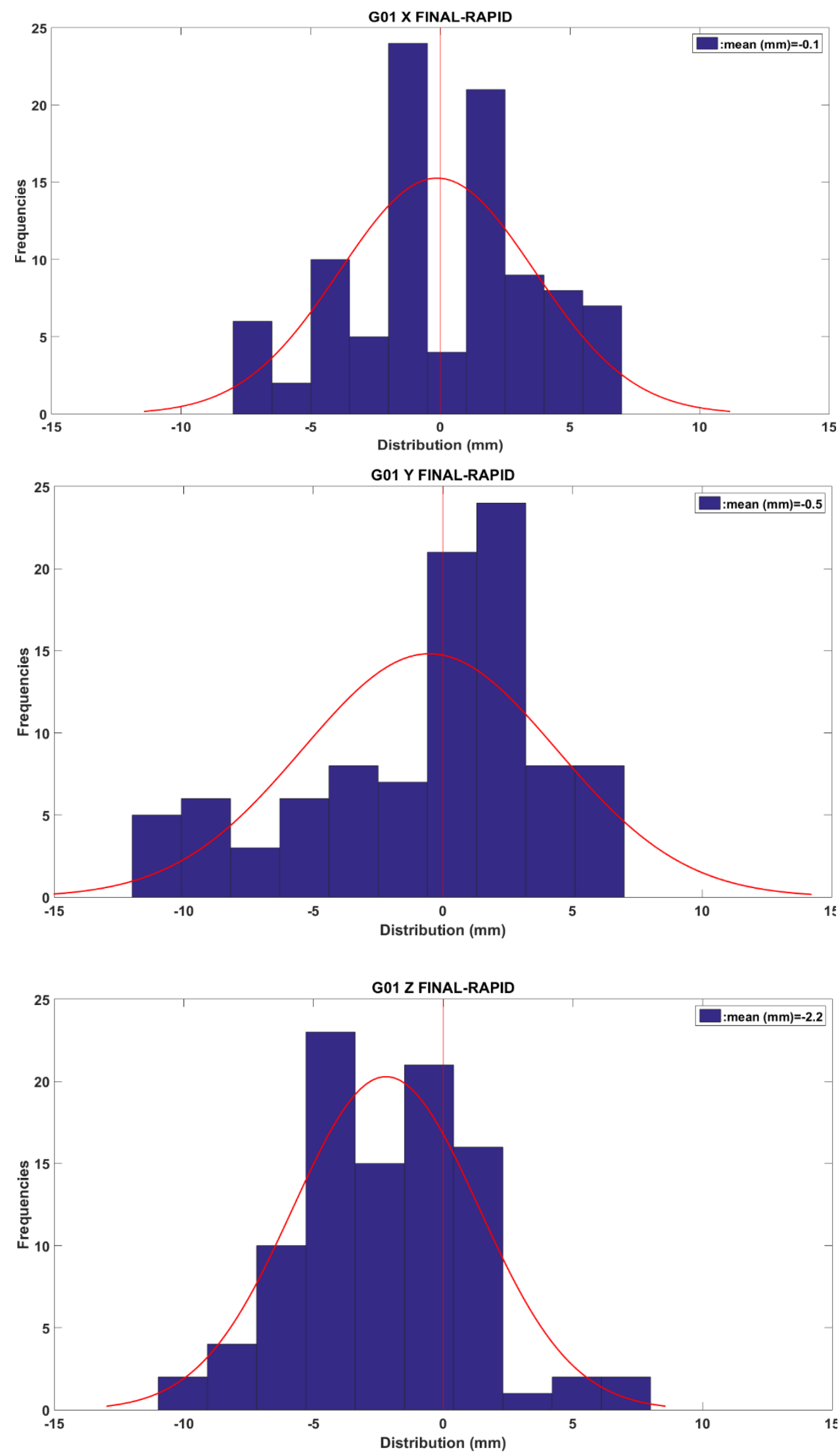

Figure 4. Distribution of ECEF differences between IGS final and rapid for 01 PRN GPS satellite 
International Journal of Engineering and Geosciences (IJEG), Vol; 5, Issue; 1, pp. 001-014, February, 2020,
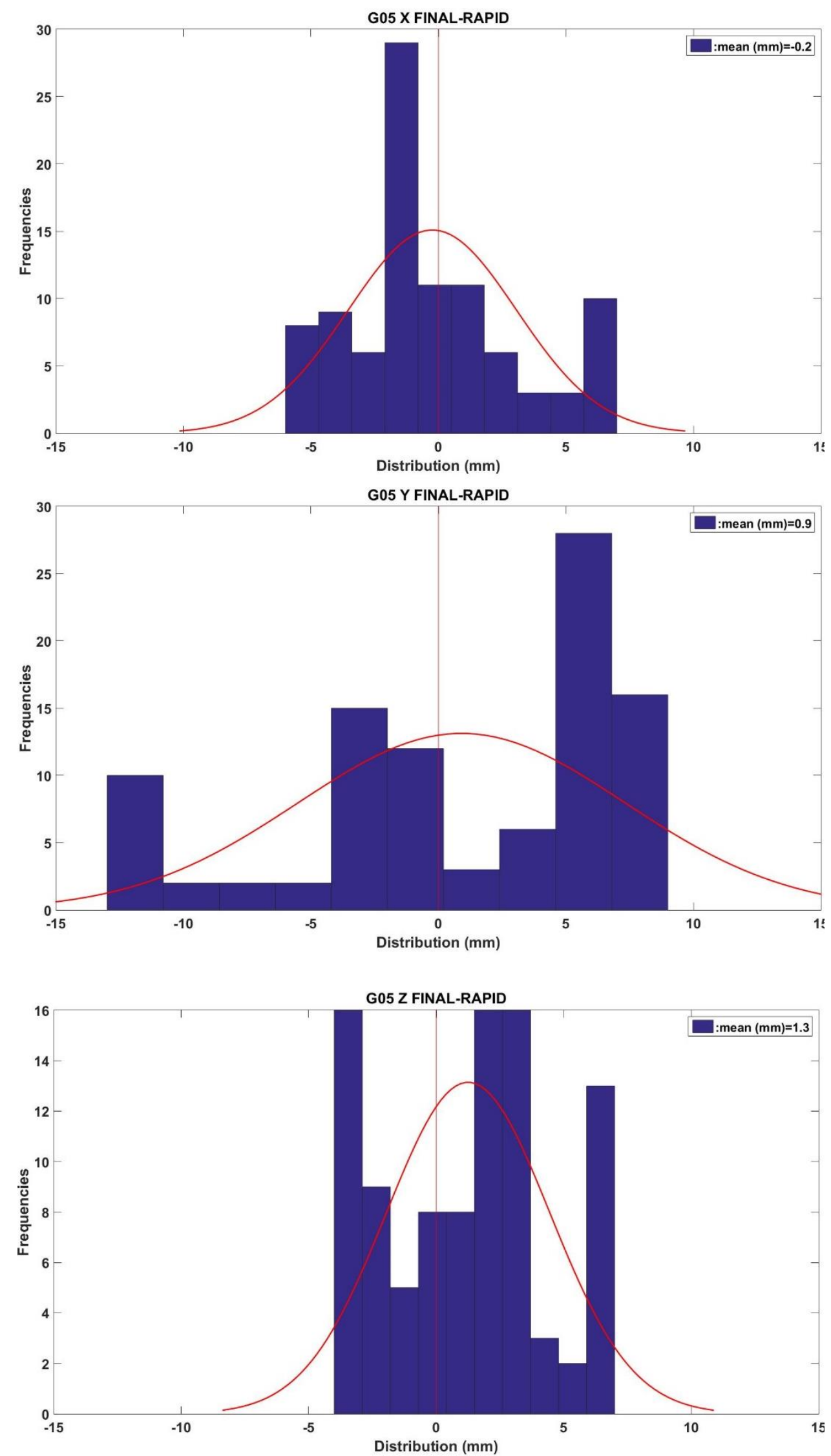

Figure 5. Distribution of ECEF differences between IGS final and rapid for 05 PRN GPS satellite 
International Journal of Engineering and Geosciences (IJEG), Vol; 5, Issue; 1, pp. 001-014, February, 2020,
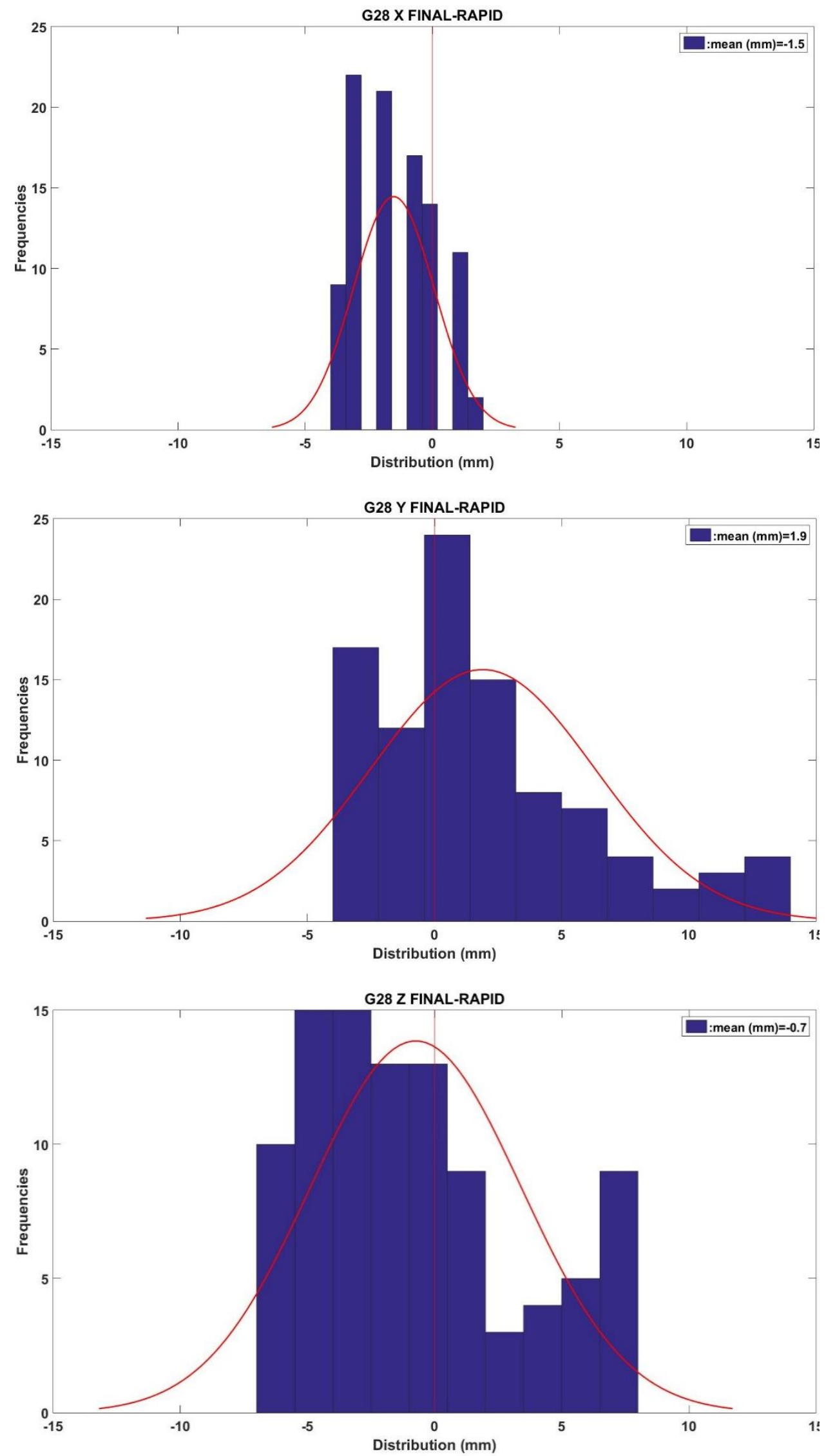

Figure 6. Distribution of ECEF differences between IGS final and rapid for 28 PRN GPS satellite 
Table 4 Thresholds range of absolute PPP horizontal differences between final and rapid products for IGS and JPL

\begin{tabular}{|c|c|c|c|c|c|c|c|c|c|c|c|c|}
\hline \multirow{2}{*}{$\begin{array}{c}\text { Thresholds of the } \\
\text { absolute differences }\end{array}$} & \multicolumn{6}{|c|}{ IGS Rapid differences (units: $\mathbf{m m}$ ) } & \multicolumn{6}{|c|}{ JPL Rapid differences (units: $\mathbf{m m}$ ) } \\
\hline & $0-1$ & $1-2$ & $2-3$ & $3-5$ & $5-10$ & $10-15$ & $0-1$ & $1-2$ & $2-3$ & $3-5$ & $5-10$ & $10-15$ \\
\hline $24 \mathrm{~h}(\%)$ & 28 & 46 & 20 & 2 & 2 & & 11 & 28 & 37 & 22 & 3 & \\
\hline $12 \mathrm{~h}(\%)$ & 27 & 40 & 23 & 6 & 3 & & 12 & 24 & 33 & 30 & 3 & \\
\hline 8 h $(\%)$ & 23 & 40 & 22 & 10 & 5 & & 9 & 26 & 32 & 29 & 6 & \\
\hline $4 \mathrm{~h}(\%)$ & 16 & 34 & 23 & 20 & 4 & & 7 & 18 & 24 & 34 & 16 & 1 \\
\hline $2 \mathrm{~h}(\%)$ & 12 & 25 & 25 & 24 & 11 & 2 & 5 & 14 & 18 & 30 & 27 & 5 \\
\hline
\end{tabular}

Table 5 Thresholds range of absolute PPP vertical differences between final and rapid products for IGS and JPL

\begin{tabular}{|c|c|c|c|c|c|c|c|c|c|c|c|c|}
\hline \multirow{2}{*}{$\begin{array}{l}\text { Thresholds of the } \\
\text { absolute differences }\end{array}$} & \multicolumn{6}{|c|}{ IGS Rapid differences (units: mm) } & \multicolumn{6}{|c|}{ JPL Rapid differences (units: $\mathbf{m m}$ ) } \\
\hline & $0-1$ & $1-2$ & $2-3$ & $3-5$ & $5-10$ & $10-15$ & $0-1$ & $1-2$ & $2-3$ & $3-5$ & $5-10$ & $10-15$ \\
\hline 24 h $(\%)$ & 60 & 34 & 9 & 2 & 2 & & 31 & 31 & 18 & 16 & 10 & \\
\hline $12 \mathrm{~h}(\%)$ & 45 & 26 & 10 & 4 & 2 & & 28 & 24 & 20 & 23 & 9 & \\
\hline 8 h $(\%)$ & 47 & 35 & 13 & 8 & 2 & & 27 & 26 & 21 & 24 & 11 & \\
\hline $4 \mathrm{~h}(\%)$ & 38 & 29 & 17 & 5 & 5 & & 22 & 22 & 21 & 24 & 16 & 2 \\
\hline $2 \mathrm{~h}(\%)$ & 31 & 26 & 18 & 17 & 11 & 2 & 16 & 16 & 15 & 25 & 26 & 4 \\
\hline
\end{tabular}

Table 6 Thresholds range of absolute PPP horizontal differences between IGS final and IGS ultra-rapid products

\begin{tabular}{|c|c|c|c|c|c|c|c|c|c|c|c|c|c|}
\hline \multirow{2}{*}{$\begin{array}{l}\text { Thresholds of the } \\
\text { absolute differences }\end{array}$} & \multicolumn{6}{|c|}{$\begin{array}{l}\text { IGS Ultra-Rapid Observed-Half differences } \\
\text { (units: } \mathbf{c m} \text { ) }\end{array}$} & \multicolumn{7}{|c|}{ IGS Ultra-Rapid Predicted-Half differences (units: cm) } \\
\hline & $0-1$ & $1-2$ & $2-3$ & $3-5$ & $5-10$ & $10-15$ & $0-5$ & $5-10$ & $10-20$ & $20-25$ & $25-30$ & $30-50$ & $50-60$ \\
\hline $24 \mathrm{~h}(\%)$ & 25 & 53 & 19 & 2 & & & 51 & 37 & 11 & & & & \\
\hline $12 \mathrm{~h}(\%)$ & 4 & 13 & 25 & 41 & 16 & & 22 & 44 & 31 & 3 & & & \\
\hline $8 \mathrm{~h}(\%)$ & 2 & 15 & 17 & 42 & 24 & & 20 & 39 & 34 & 5 & 2 & & \\
\hline $4 \mathrm{~h}(\%)$ & 4 & 7 & 13 & 33 & 42 & & 10 & 26 & 41 & 8 & 5 & & \\
\hline $2 \mathrm{~h}(\%)$ & 4 & 8 & 11 & 32 & 44 & 2 & 7 & 19 & 34 & 11 & 8 & 14 & 5 \\
\hline
\end{tabular}

Table 7 Thresholds range of absolute PPP vertical differences between IGS final and IGS ultra-rapid products

\begin{tabular}{|c|c|c|c|c|c|c|c|c|c|c|c|c|c|}
\hline $\begin{array}{l}\text { Thresholds of the } \\
\text { absolute differences }\end{array}$ & \multicolumn{5}{|c|}{$\begin{array}{l}\text { IGS Ultra-Rapid Observed-Half } \\
\text { differences (units: } \mathbf{c m} \text { ) }\end{array}$} & \multicolumn{8}{|c|}{ IGS Ultra-Rapid Predicted-Half differences (units: cm) } \\
\hline $24 \mathrm{~h}(\%)$ & 2 & 74 & 25 & & & 28 & 32 & 36 & 3 & & & & \\
\hline $8 \mathrm{~h}(\%)$ & 17 & 52 & 24 & 7 & & 23 & 24 & 35 & 8 & 5 & 4 & 2 & \\
\hline $4 \mathrm{~h}(\%)$ & 18 & 50 & 22 & 9 & & 22 & 19 & 29 & 8 & 8 & 9 & 2 & \\
\hline $2 \mathrm{~h}(\%)$ & 27 & 42 & 20 & 7 & 3 & 16 & 16 & 27 & 11 & 8 & 10 & 7 & 5 \\
\hline
\end{tabular}

Tables 4-5 show the percentage of thresholds range of the absolute PPP horizontal and vertical differences between final and rapid products for IGS and JPL. The threshold range represents the minimum and maximum absolute differences between PPP results using final and rapid/ultra-rapid products. For example, 0-1 in Table 4 indicates the ratio of absolute differences that are bigger than or equal to $0 \mathrm{~mm}$ and less than or equal to $1 \mathrm{~mm}$, among all the absolute differences with respect to each session. Tables 6-7 show the percentage of thresholds range of the absolute PPP horizontal and vertical differences between IGS final and IGS ultra-rapid products. The same thresholds range scale was not given for IGS ultra-rapid products due to the high difference between the products. Since the results of JPL rapid and ultra-rapid products are similar, JPL ultra-rapid percentage of thresholds range is omitted for convenient comparison.
The results of thresholds range indicate that PPP horizontal and vertical coordinate differences between final and the other products increases significantly as the duration of observing sessions decreases. The differences become more obvious especially for IGS ultra-rapid products. For example, maximum range was computed as $10-20 \mathrm{~cm}$ for $24 \mathrm{~h}$ IGS ultra-rapid predicted-half $(11 \%$ of all residuals) whereas for $2 \mathrm{~h}$ observing session, maximum range reached was $50-60 \mathrm{~cm}(5 \%$ of all residuals) for the horizontal component.

Besides relative accuracy, precision of PPP using IGS/JPL products were also investigated for three IGS stations. 24-12-4 h sessions were chosen for comparison. Figure 7 shows the horizontal and vertical precision values of PPP results using final, rapid and ultra-rapid IGS/JPL products. Due to the similar results between JPL rapid and ultra-rapid products, the results of JPL ultrarapid are omitted 


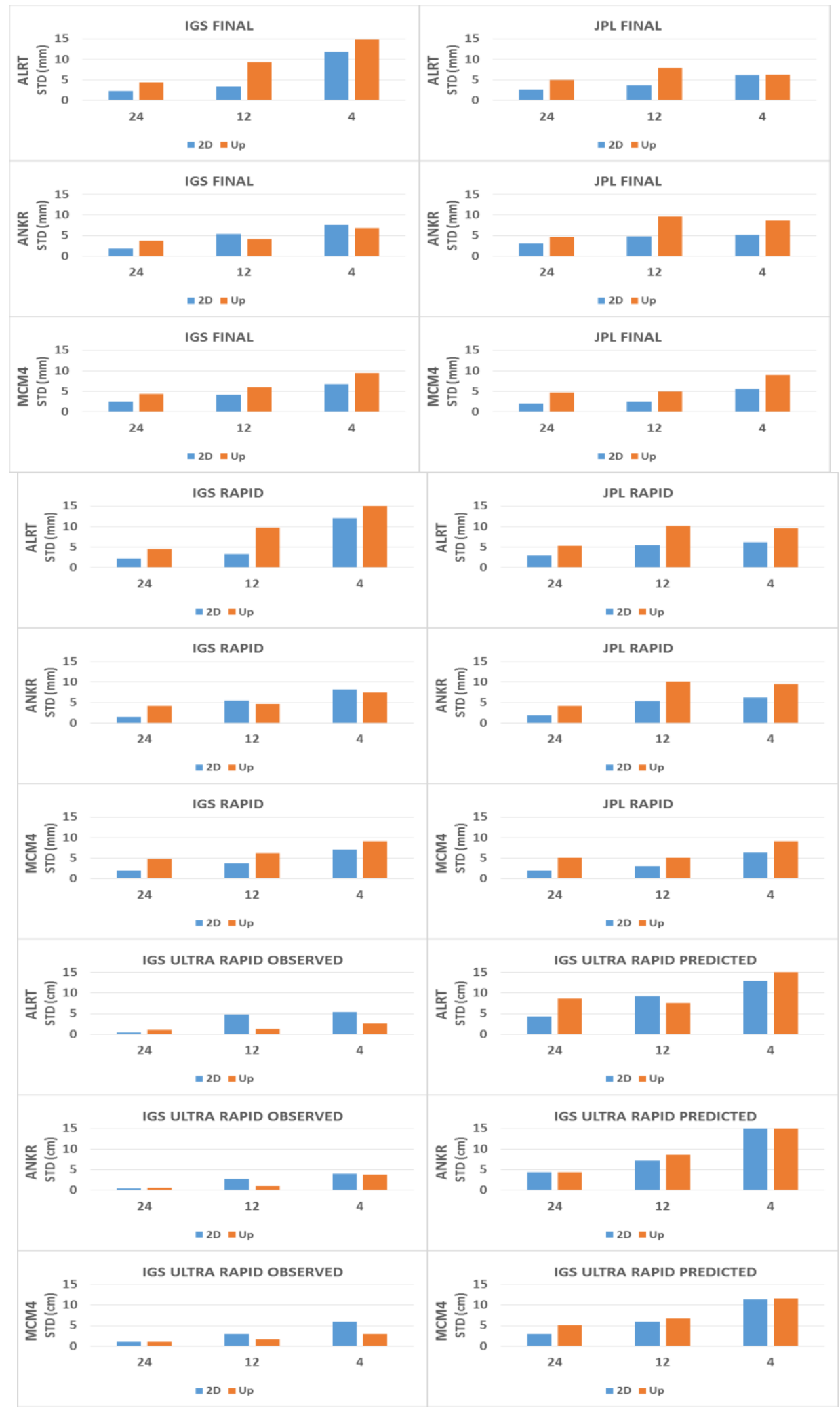

Figure 7. Precision values of PPP using IGS/JPL products 
For an intuitive interpretation of the relative location of the satellites from different orbit products, local radial $\left(e_{R_{-} r e f}\right)$, along-track $\left(e_{A_{-} r e f}\right)$ and cross-track $\left(e_{C_{-} r e f}\right)$ reference frame (local orbital frame) can be used. The corresponding unit vectors of this reference frame can be computed as follows (Montenbruck et al, 2002);

$$
\begin{aligned}
& \boldsymbol{e}_{R_{-} r e f}=\frac{\boldsymbol{r}}{|\boldsymbol{r}|} \\
& \boldsymbol{e}_{C_{-} r e f}=\frac{\boldsymbol{r} \times \dot{\boldsymbol{r}}}{|\boldsymbol{r} \times \dot{\boldsymbol{r}}|} \\
& \boldsymbol{e}_{\boldsymbol{A}_{-} \text {ref }}=e_{C_{-} r e f} \times e_{R_{-} r e f}
\end{aligned}
$$

$$
\left[\boldsymbol{e}_{\boldsymbol{a}} \boldsymbol{e}_{\boldsymbol{c}} \boldsymbol{e}_{\boldsymbol{r}}\right]=\left[e_{R_{-} r e f} e_{C_{-} r e f} e_{A_{-} r e f}\right]^{-1} * \delta_{X Y Z_{E C E F}}
$$

where $\mathrm{r}$ and $\dot{\boldsymbol{r}}$ are the satellite position and inertial velocity vector from the final ephemeris and $\boldsymbol{\delta}_{X Y Z_{E C E F}}$ is the ECEF coordinate differences between the final and the other associated products.

Table 8 shows the average RMSE values of the radial, along-track and cross-track components of all GPS satellites for IGS/JPL rapid and ultra-rapid products relative to the final product for 31 consecutive days.

\begin{tabular}{|c|c|c|c|c|c|c|c|c|c|c|c|c|c|c|}
\hline \multicolumn{3}{|c|}{ IGS Rapid } & \multicolumn{3}{|c|}{ JPL Rapid } & \multicolumn{3}{|c|}{$\begin{array}{l}\text { IGS Ultra-Rapid } \\
\text { Observed-Half }\end{array}$} & \multicolumn{3}{|c|}{ JPL Ultra-Rapid } & \multicolumn{3}{|c|}{$\begin{array}{l}\text { IGS Ultra-Rapid } \\
\text { Predicted-Half }\end{array}$} \\
\hline $\mathrm{R}$ & A & C & $\mathrm{R}$ & A & C & $\mathrm{R}$ & $\mathrm{A}$ & $\mathrm{C}$ & $\mathrm{R}$ & A & C & $\mathrm{R}$ & $\mathrm{A}$ & $\mathrm{C}$ \\
\hline 4 & 6 & 6 & 9 & 11 & 10 & 7 & 12 & 11 & 10 & 14 & 12 & 10 & 53 & 56 \\
\hline
\end{tabular}
Computations were performed using orbit overlap analysis software in GIPSY/OASIS.

Table 8 Average RMSE values of radial, along-track and cross-track components of all GPS satellites (Units: mm)

Table 8 indicates that orbital errors are much higher in along-track and cross-track components compared to the radial component. It is understood from the results of the orbit errors that satellite clock errors affect the accuracy of PPP more significantly than the orbit errors. This situation is much more evident for the IGS ultrarapid observed-half product.

\section{CONCLUSION}

PPP is a relatively new approach compared to differential positioning for $\mathrm{mm}$ to $\mathrm{cm}$ level accuracy in static positioning using a single geodetic-grade GNSS receiver and predetermined precise satellite orbit and clock products. Since the satellite orbit and clock errors directly affect the station coordinates for PPP technique, the choice of orbit and clock products play a significant role in PPP. In this paper, the relative accuracy of rapid and ultra-rapid orbit and clock products from two commonly used GNSS analysis centers, IGS combined and JPL individual, were investigated for PPP horizontal and vertical coordinates while their final products were taken as the true value. 24-12-8-4-2 hours of nonoverlapping sessions of GPS observations in 31 consecutive days were processed using IGS/JPL final, rapid and ultra-rapid products for ten IGS stations distributed around the world.

The results show that the relative horizontal and vertical accuracy of PPP using rapid and ultra-rapid products decreases as the observation session becomes shorter. It is believed that since the same part of nonoverlapping arc-lengths was compared between the final and the other products, distribution of the orbit errors (similar to normal distribution) is mainly responsible for this phenomenon.

RMSE of PPP horizontal and vertical coordinates indicate that mm-level horizontal and vertical relative accuracies with respect to PPP using the final product can be obtained using IGS/JPL rapid and JPL ultra-rapid products. RMSE of JPL rapid and ultra-rapid products are nearly identical and this is very beneficial for near-real time users who need mm-level accuracy. IGS ultra-rapid observed-half and predicted-half products can provide $\mathrm{cm}$ to dm-level relative accuracy with respect to the IGS final product. It should be emphasized that the most current available parts of IGS ultra-rapid products with respect to the observation sessions were used for PPP processes. The accuracy would be much lower if the out of date ultra-rapid products with respect to the observing sessions were used. In this study, $300 \mathrm{sec}$ sampling interval was used for each process; thus, third-order polynomial interpolation was conducted only for IGS ultra-rapid clock products. If less than $300 \mathrm{sec}$ sampling interval is used for the processes, clock interpolation error might have occurred for the other products. As a result, RMSE of PPP using IGS/JPL rapid and JPL ultra-rapid products may be increased. The difference between horizontal and vertical RMSE is much more evident for IGS ultra-rapid products. PPP relative vertical accuracy is significantly lower than relative horizontal accuracy for IGS ultrarapid products while PPP relative horizontal and vertical accuracies are similar for the other products. Since IGS ultra-rapid clocks interval is $15 \mathrm{~min}$, its relative accuracy is expected to be much lower than JPL ultra-rapid relative accuracy.

It should be emphasized that PPP processing model for orbit and clock between IGS and JPL is different. In this study, only the relative accuracy of rapid and ultrarapid IGS/JPL products with respect to theirs final products were evaluated. Since the absolute accuracy of rapid and ultra-rapid products is not the scope in this paper, the difference in PPP processing strategy for orbit and clock products between IGS and JPL does not affect the overall result of relative accuracies.

The results of the threshold ranges show that nearly $100 \%$ of absolute horizontal and vertical differences are within 0-5 mm for IGS and JPL rapid/ultra-rapid products if $24 \mathrm{~h}$ observing sessions are used. The maximum difference reached 15 and $25 \mathrm{~cm}$ for $24 \mathrm{~h}$ IGS ultra-rapid observed-half and predicted-half products, respectively. As it is expected the differences are getting higher as observing sessions become shorter. For example, the maximum horizontal absolute difference is $20 \mathrm{~cm}$ and 60 
$\mathrm{cm}$ for 24 and $2 \mathrm{~h}$ sessions, respectively, using IGS ultrarapid predicted-half products.

Radial, along-track and cross-track components of rapid and ultra-rapid products indicate that relative satellite clock errors rather than the relative orbit errors are mainly responsible for the coordinate differences with respect to PPP using final products. It can also be concluded from the results that orbit errors are mainly lumped in the along-track and cross-track components for IGS/JPL rapid and ultra-rapid products.

The author believes that this study has contributed to the impact of rapid and ultra-rapid orbit and clock products on the PPP coordinates while taking into consideration the trade-off between the relative accuracy and time delay with respect to final product.

\section{ACKNOWLEDGEMENTS}

The authors would like to express their gratitude to NASA Jet Propulsion Laboratory (JPL) for providing GIPSY/OASIS scientific software.

\section{REFERENCES}

Alcay, S., Ogutcu, S., Kalayci, I and Yigit, C.O. (2019). Displacement monitoring performance of relative positioning and Precise Point Positioning (PPP) methods using simulation apparatus, Advances in Space Research $63,5,1697-1707$.

Bertiger, W., Desai, S. D., Haines, B., Harvey, N., Moore, A. W., Owen, S., and Weiss, J. P. (2010). Single receiver phase ambiguity resolution with GPS data. Journal of Geodesy, 84(5), 327-337.

Dow, J. M., Neilan, R. E and Rizos, C. (2009). The international GNSS service in a changing landscape of global navigation satellite systems. Journal of geodesy, 83(3-4), 191-198.

Gao, Y and Chen, K., (2004). Performance analysis of precise point positioning using rea-time orbit and clock products. Positioning, 1(08), 0.

Geng, J., Teferle, F. N., Shi, C., Meng, X., Dodson, A. H and Liu, J. (2009). Ambiguity resolution in precise point positioning with hourly data. GPS solutions, 13(4), 263270.

Hayal, A. G and Sanli, D. U (2016). Revisiting the role of observation session duration on precise point positioning accuracy using GIPSY/OASIS II Software. Boletim de Ciências Geodésicas, 22 (3), 405-419.

Lagler, K., Schindelegger, M., Böhm, J., Krásná, H., and Nilsson, T. (2013). GPT2: Empirical slant delay model for radio space geodetic techniques. Geophysical research letters, 40(6), 1069-1073.

$\mathrm{Lu}, \mathrm{F}$ and $\mathrm{Li}, \mathrm{J}$ (2011). Precise point positioning study to use different igs precise ephemeris. In Computer Science and Automation Engineering (CSAE), 2011 IEEE International Conference, 3, 592-595.

Martín, A., Anquela, A. B., Capilla, R and Berné, J. L (2010). PPP technique analysis based on time convergence, repeatability, IGS products, different software processing, and GPS+ GLONASS constellation. Journal of Surveying Engineering, 137(3), 99-108.

Montenbruck, O., Steigenberger, $\mathrm{P}$ and Hauschild, A. (2015). Broadcast versus precise ephemerides: a multiGNSS perspective. GPS solutions, 19(2), 321-333.

Montenbruck, O., Ebinuma, T., Lightsey, E. G and Leung, S. (2002). A real-time kinematic GPS sensor for spacecraft relative navigation. Aerospace Science and Technology, 6(6), 435-449.

Rebischung, P and Schmid, R. (2016). IGS14/igs14. atx: a new framework for the IGS products. In AGU Fall Meeting 2016.

Park, J. K and Jung, K. Y. (2014). Accuracy Analysis of Influences by Satellite Ephemeris. Contemporary Engineering Sciences, 7(24), 1.

Şentürk, E and Erener, A. (2017). Determination Of Temporary Shelter Areas In Natural Disasters By Gis A Case Study For Gölcük/Turkey. International Journal of Engineering and Geosciences, 2(3), 84-90.

Shi, J., Wang, G., Han, X and Guo, J. (2017). Impacts of Satellite Orbit and Clock on Real-Time GPS Point and Relative Positioning. Sensors, 17(6), 1363.

Springer, T. A and Hugentobler, U. (2001). IGS ultra rapid products for (near-) real-time applications. Physics and Chemistry of the Earth, Part A: Solid Earth and Geodesy, 26(6-8), 623-628.

Tusat, E and Ozyuksel, F. (2018). Comparison of GPS satellite coordinates computed from broadcast and IGS final ephemerides. International Journal of Engineering and Geosciences, 3(1), 12-19.

Yigit, C. O and Gurlek, E. (2017). Experimental testing of high-rate GNSS precise point positioning (PPP) method for detecting dynamic vertical displacement response of engineering structures. Geomatics, Natural Hazards and Risk, 8(2), 893-904.

Zumberge, J. F., Heflin, M. B., Jefferson, D. C., Watkins, M. M and Webb, F. H. (1997). Precise point positioning for the efficient and robust analysis of GPS data from large networks. Journal of geophysical research: solid earth, 102(B3), 5005-5017. 